\title{
Secondary adrenocortical insufficiency and renal impairment in a patient presenting with hyperprolactinemia
}

\author{
Authors: M Waseem Aslam, Jonathan Rippin; waseem.aslam@nhs.net \\ Department of Diabetes and Endocrinology Northampton General Hospital. Northampton NN1 5BD
}

\section{Introduction}

Primary hypothyroidism has been described as a precursor to pituitary hyperplasia in literature.

Resulting pituitary hyperplasia can cause hyperprolactinemia by stalk effect or can affect other hormonal axis.

Following adequate hormone replacement with L-thyroxine both symptoms and pituitary hyperplasia

regressed on average within a few months

\section{Case Report}

We report a case of 19 year old lady who was referred to endocrine clinic with galactorrhoea associated with hyperprolactinemia. An MRI, arranged by GP, had had revealed an enlarged pituitary with a $14 \times 8 \mathrm{~mm}$ macroadenoma slightly distorting the optic chiasma. Visual fields were normal on confrontation but showed restricted fields in both eyes on Goldman perimetry. She was commenced on cabergoline to which her galactorrhoea responded quickly. On subsequent visit her profile revealed severe primary hypothyroidism (TSH- 742mU/L and fT4<3.4). Cortisol was $283 \mathrm{nmol} / \mathrm{L}$; gonadotrophins were normal, as was her IGF-1. Her creatinine was raised despite her slender built. Creatine Kinase was moderately elevated (297iU/L). She was commenced on Levothyroxine 50ug OD (later on increased) along with hydrocortisone (15mg am. $10 \mathrm{mg}$ midafternoon). A short synacthen test, carried out less than 2 weeks after starting hydrocortisone, showed an abnormal response. Her subsequent ACTH (after omitting hydrocortisone the previous evening and delaying the morning does till after the test) was $17.1 \mathrm{ng} / \mathrm{L}$; cortisol was 30 $\mathrm{nmol} / \mathrm{L}$ at the time. Adrenal antibodies were negative. In due course with improvement in thyroid function her visual fields improved on perimetry with slight regression in size of pituitary gland.

\section{Conclusions}

Her primary Hypothyroidism appears to have caused compensatory pituitary hyperplasia with associated hyperprolactinemia due to high $\mathrm{TRH}+/$ - pituitary stalk compression. Her pituitary hyperplasia appears to have caused secondary adrenal insufficiency. Pathophysiology of impaired renal function in hypothyroidism is multifactorial; the reduction in GFR due to the lower cardiac output and renal blood flow is likely to be the predominant mechanism

\begin{tabular}{|l|c|c|}
\hline \multicolumn{3}{|c|}{ Investigations } \\
\hline & At presentation & After 7 months \\
\hline Prolactin mu/L & 1074 & \\
\hline TSH mu/L & 742 & 342 \\
\hline T4 pmol/L & $<3.9$ & 71 \\
\hline T3 pmol/L & $<1.5$ & 10.1 \\
\hline eGFR & 45 & 3.1 \\
\hline Creatinine umol/L & 148 & 76 \\
\hline Cortisol nmol/L & Omin-108 30min-289 & $90 \mathrm{~min}-390$ \\
\hline
\end{tabular}

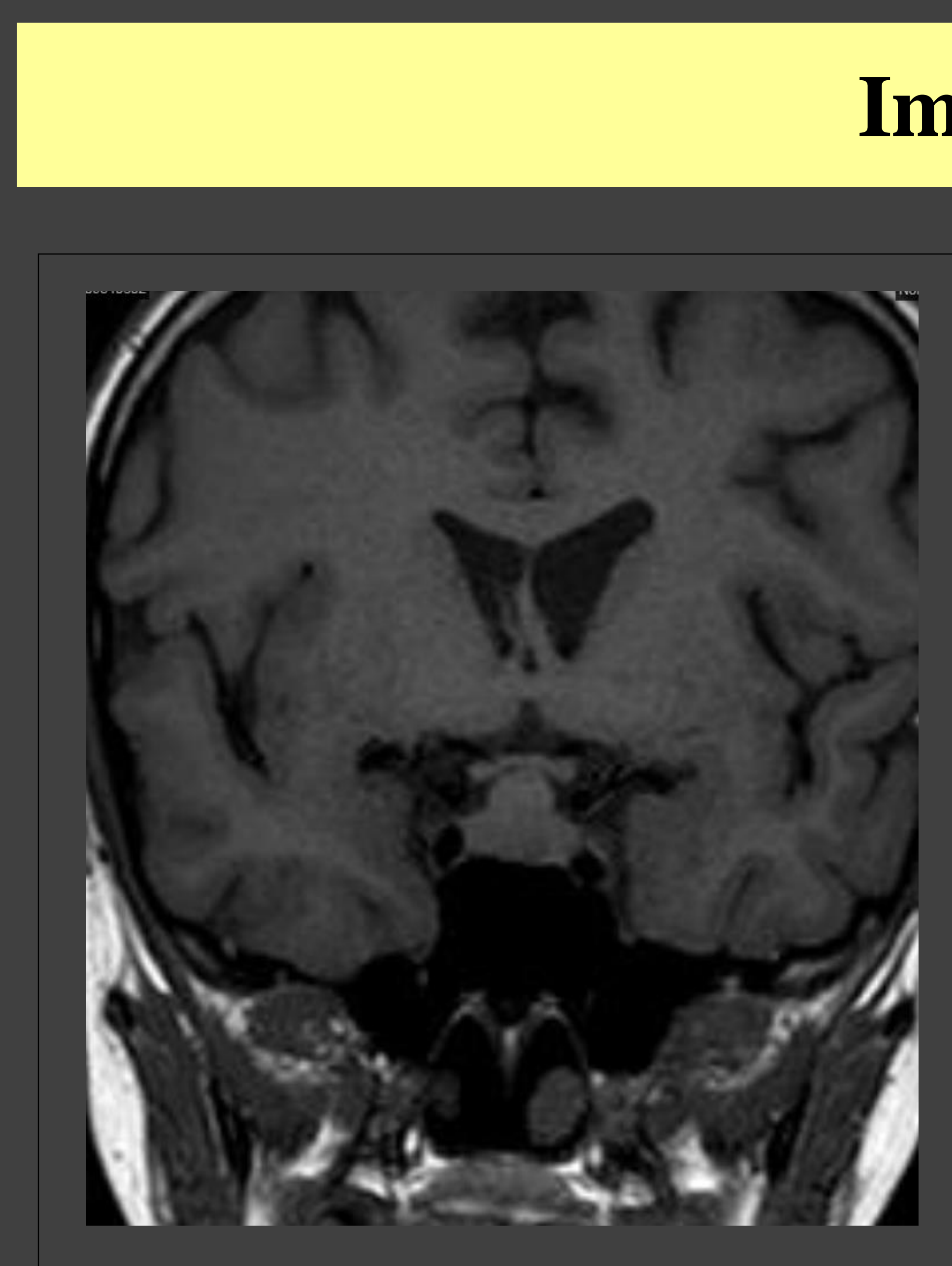

At Presentation

\section{Imaging}

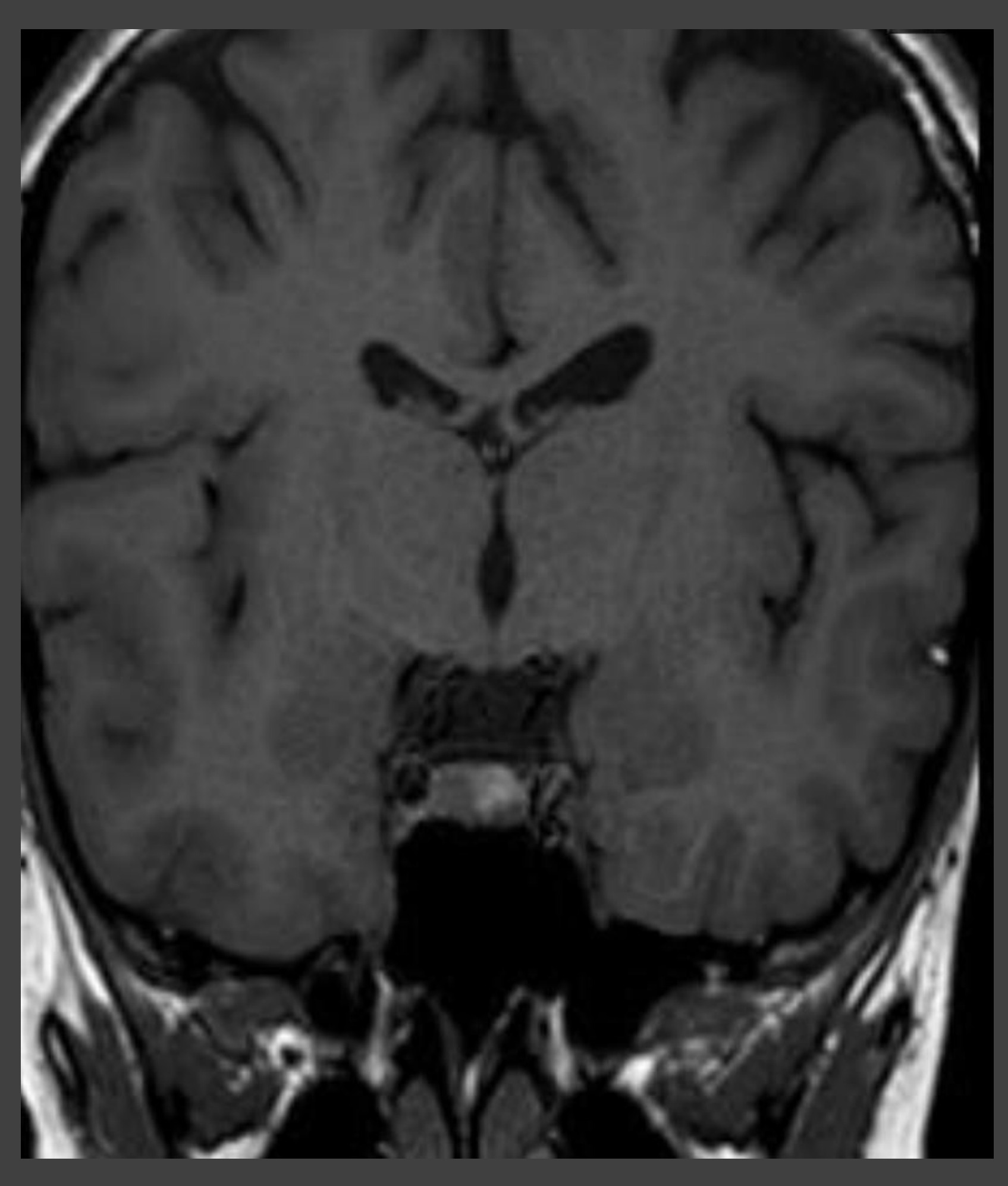

Follow up

\section{References}

\footnotetext{
1 .Nicholas WC, Russell WF. Primary hypothyroidism presenting as a pituitary mass. J Miss State Med Assoc. 2000;41:511-4. [PubMed]

2: Renal impairment resulting from hypothyroidism; Andrew Connor Joanne $\mathrm{E}$ Taylor; NDT Plus, Volume 1, Issue 6, 1 December 2008, Pages 440-441 3: Young M, Kattner K, Gupta K. Pituitary hyperplasia resulting from primary hypothyroidism mimicking macroadenomas. Br J Neurosurg. 1999;13:13842. [PubMed]

4: Joshi AS, Woolf PD. Pituitary hyperplasia secondary to primary hypothyroidism: a case report and review of the literature. Pituitary. 2005;8:99-103. doi 10.1007/s11102-005-3281-8. [PubMed]
} 